\title{
Nonlinear analysis of reinforced concrete hollow beam with GFRP bars and stirrups using finite element method under cyclic load
}

\begin{abstract}
Insufficient knowledge on using fibre-reinforced polymer (FRP) materials in hollow members limits their application. Torsional load results in the less efficient hollow section that plays an important role in hollow members. This load is generated on the members by an external load. The torsional load in hollow members that are reinforced longitudinally with FRP has been discussed for years. However, research on high-strength concrete (HSC) reinforced with glass fibre-reinforced polymer (GFRP) is scarce. Therefore, in this study, the behaviour of hollow beam internally reinforced with GFRP bars under cyclic load is investigated. For this purpose, the HSC-reinforced concrete hollow beam with GFRP bars and hollow beam with normal reinforcement are considered and finite element model is developed and nonlinear dynamic analysis has been conducted by applying cyclic loads to the developed models. In addition, reinforced concrete (RC) solid beam with HSC material is tested experimentally in order to verify and validate the ability of finite element software to predict the result. The analysis results are investigated in terms of the hysteresis loop, stress and strain distribution in the beam and it is indicated that the performance of hollow beam reinforced with GFRP bars and stirrups has improved in comparison with HSC beam with GFRP bars and also HSC beam with normal steel reinforcement. Therefore, based on this research, it is recommended to implement GFRP bars and stirrup for strengthening the concrete members in the high humidity areas where use of normal steel is not feasible due to corrosion threat.
\end{abstract}

Keyword: Cyclic load; Finite element; Hollow beam; High-strength concrete; Glass fibrereinforced polymer bars 